Journal of

Women's Health and Gynecology

\title{
The Uterine Artery Pseudoaneurysm- A Challenging Diagnosis in Second- ary PPH After Caesarean Section- Case Report and Literature Review
}

\author{
Manuela Heim ${ }^{*}$, , Alexandra Moldovan ${ }^{2}$, Alyson Hunter ${ }^{3}$ \\ ${ }^{1}$ Royal Maternity Hospital Belfast Trust, United Kingdom \\ ${ }^{2}$ Royal Victoria Hospital Belfast, Radiology Department \\ ${ }^{3}$ Consultant obstetrician, Royal Maternity Hospital Belfast
}

${ }^{\star}$ Corresponding author: Manuela Heim, Royal Maternity Hospital Belfast Trust, United Kingdom, Tel: 004-475-921-774-92, E-mail: heimmanuela@yahoo.com

Received Date: March 21, 2019 Accepted Date: April 09, 2019 Published Date: April 11, 2019

Citation: Manuela Heim (2019) The Uterine Artery Pseudoaneurysm- A Challenging Diagnosis in Secondary PPH After Caesarean Section- Case Report and Literature Review. J Womens Health Gyn 6: 1-3.

\section{Background}

Uterine artery pseudoaneurysm (UAP) is a potentially life-threatening complication that can occur after a uterine surgery, dilatation and curettage, traumatic delivery (such as forceps or vacuum delivery) or after other causes of vascular trauma, the most common being a caesarean section (C/S) [1-4]. Some UAP can appear many years after a uterine surgery $[2,5]$ or even after a nontraumatic delivery/abortion or manual removal of the placenta $[3,4]$.

The UAP is not as rare as previously considered. On 50 cases in a single institute experience, the incidence of UAP was estimated as 3-6/1000 deliveries [7,8].

UAP is a collection of blood in the myometrium, fully covered by the adventitia or the surrounding tissues, with turbulent flow that is fed by arterial blood flow through a defect in the wall of uterine artery. Hormonal and haemodynamic changes are the triggers of this complication in pregnancy or postpartum [2]. The differential diagnosis is mainly with acquired and congenital arterio-venous malformations (AVM). If the diagnosis is delayed it can result in a sudden lifethreatening haemorrhage, even many weeks after the caesarean section.

The diagnosis can be challenging, as the most common cause of the secondary postpartum haemorrhage (PPH) is the postpartum endometritis with or without retained products of conception (RPOC). In the setting of an emergency the patient would usually be treated with antibiotics and even an evacuation of suspected RPOC which could be devastating, ending with a fulminant intractable haemorrhage resulting in an emergency hysterectomy or even death.

The gold standard for diagnosis is the computed tomography (CT) angiography, but the Colour Doppler ultrasound [6] and the magnetic resonance imaging (MRI) could be used as well. The main disadvantage of the CT angiography is the exposure to radiation and the possible reaction to the medium contrast.

The treatment of choice is the uterine artery embolization, but there are reported cases of laparoscopic and hysteroscopic treatment as well [2,5]. In the era when the trans arterial embolization was not as widely used as at present, the only available treatment was the hysterectomy.

(C)2019 The Authors. Published by the JScholar under the terms of the Creative Commons Attribution License http://creativecommons.org/licenses/ by/3.0/, which permits unrestricted use, provided the original author and source are credited. 


\section{Case Report}

We present a case of a 25year-old para1 woman diagnosed with UAP. She has had three episodes of PPH. First one was a primary $\mathrm{PPH}$ due to atony approximately $1 \mathrm{~h}$ after an emergency caesarean section for failure of progress and nonreassuring cardiotocography (CTG). It was a prolonged labour complicated by hyperstimulation treated with two doses of terbutaline during the labour. The total blood loss was 31 .

The haemorrhage was successfully treated with uterotonics (syntocinon, ergometrine, misoprostol, haemobate) and a Rusch balloon was inserted prophylactically for $24 \mathrm{~h}$. She was transfused with 1 unit of packed red cell. The patient recovered quickly and was discharged on day 3 postpartum with minimal bleeding and $\mathrm{Hb} 92$.

Three weeks postpartum she was brought by ambulance with a heavy haemorrhage and was readmitted to the hospital for suspicion of retained products of conception (RPOC) and endometritis. She was treated with uterotonics, intravenous (IV) fluids and antibiotics. On the transvaginal ultrasound scan (TVUSS) the cavity was full of clots which were interpreted as RPOC and the plan was for surgical evacuation. The procedure was postponed to the next morning, as the bleeding settled after couple of hours. In the meantime, the plan was to continue the IV antibiotics.

The next morning, the TAUSS was repeated and the uterus was found empty. The bleeding was minimal, so the surgical procedure was cancelled and the patient was discharged on antibiotics and iron. Hb was 90.

Six weeks postpartum she had another fulminant haemorrhage and she was brought to the hospital by ambulance with the BP of $80 / 46 \mathrm{mmHg}$. She was successfully treated with IV fluids and uterotonics. She had a transabdominal ultrasound scan (TAUSS) at the emergency department which failed to find any cause. The cavity was full of clots again, but no obvious cause of bleeding was detected. The bleeding settled.

The next day an ultrasound Doppler scan was performed and an anechoic structure $(1.5 \times 2.9 \mathrm{~cm})$ with turbulent blood flow within the uterine wall on the right side of the previous $\mathrm{C} / \mathrm{S}$ scar was revealed. The patient was referred to radiology for an urgent CT angiogram.
The CT angiogram revealed on the arterial phase study a well-defined $1.5 \mathrm{~cm}$ focus of contrast extravasation within the right aspect of the uterine wall. Following this back, it appeared to arise from the right uterine artery. On the portovenous study there was no dissipation of the contrast, findings consisting with pseudoaneurysm formation. In conclusion an UAP was diagnosed.

The case was discussed with the interventional radiologist and an urgent embolization with gel foam of the right uterine artery was done in the same day. The angiogram demonstrated uterine artery pseudoaneurysm and the 5 mins delayed angiogram demonstrated good embolization. Further right internal iliac artery (IIA) angiogram was satisfactory. There was no immediate post-procedural complication.

The ultrasound Doppler examination done 3 days later confirmed the successful embolization of the right uterine artery and of the pseudoaneurysm. The patient was discharged next day with spotting. The Doppler ultrasound done after 6-8 weeks ensured that there was no recurrence.

\section{Conclusion}

Although a recent study on a large number of cases revealed that UAP can occur much more frequently than previously believed, this condition is still not well known among obstetricians.

The UAP is a challenging diagnosis. In the setting of an emergency, the most common management of a secondary PPH would be a surgical evacuation of the suspected RPOC, which can exacerbate the bleeding by damaging the pseudoaneurysm. The haemorrhage can sometimes only be stopped by hysterectomy if the uterine artery embolization is not possible in the emergency.

We would like to highlight the importance of accurate ultrasound diagnosis in the setting of a secondary postpartum haemorrhage, before any surgical decision is made, in order to avoid severe morbidity and mortality by massive haemorrhage. Obstetricians should be aware that UAP is an important cause of postpartum and postabortal haemorrhage. This condition should always be considered as a differential diagnosis in any case of recurrent or heavy uterine bleeding after a history of uterine trauma [2-4], or even in asymptomatic patients with any pelvic mass after C/S [1]. The Doppler ultrasound should always be used in such cases. 


\section{References}

1. Kuwata T, Matsubara S, Kaneko Y, Izumi A, Nakata M, Suzuki M. (2010) Asymptomatic uterine artery pseudoaneurysm after caesarean section. J Obstet Gynaecol Res. 2:40510 .

2. Michael Ciebiera, Aneta Slabuszewska-Jozwiak, Grzegorz Jakiel. (2017) Management of Uterine Artery Pseudoaneurysm: Advanced ultrasonography imaging and laparoscopic surgery as an alternative method to angiocomputed tomography and trans arterial embolization. Wideochir Inne Maloinwazyjne, 1: 106-109

3. Nagayama C, Gibo M, Nitta H, Uezato T, Hirakawa M, Masamoto H, et.al. (2011) Aoki Rupture of pseudoaneurysm after vaginal delivery successfully treated by selective arterial embolization. Arch Gynecol Obstet. 1:37-40.

4. Kim YA1, Han YH, Jun KC, Jeon MK, Lee ES. (2008) Uterine artery pseudoaneurysm manifesting delayed postabortal bleeding. Fertil Steril. 3: 849.e11-4.

5. N. Papadakosa, L. Walesa, K. Hayesb, A.-M. Bellic, I. Loftusa, S. Raya (2008) Post-traumatic Pelvic Pseudoaneurysm and Arterio-venous Fistula: Combined Endovascular and Surgical Approach. Eur J Society for Vascular Surgery 2:164-6.

6. Timmerman D1, Wauters J, Van Calenbergh S, Van Schoubroeck D, Maleux G, Van Den Bosch T, et.al. (2003) Colour Doppler imaging is a valuable tool for the diagnosis and management of uterine vascular malformations. Ultrasound Obstet Gynecol. 6:570-7.

7. Baba Y et al. (2016) Uterine artery pseudoaneurysm: it's occurrence after non-traumatic events and possibility of “without embolization" strategy. j. ejogrb. 205:72-8

8. Matsubara S et al. (2014) Arch 289:469-70.

Submit your manuscript to a JScholar journal and benefit from:

ฯ Convenient online submission

ฯ Rigorous peer review

q Immediate publication on acceptance

ฯ Open access: articles freely available online

ब High visibility within the field

ब Better discount for your subsequent articles

Submit your manuscript at http://www.jscholaronline.org/submit-manuscript.php 